\title{
O SETOR DE ESPORTE PARA O DESENVOLVIMENTO E A PAZ: UM MODELO SOCIOLÓGICO DE AGÊNCIAS PACIFICADORAS ${ }^{1}$
}

\author{
Richard Giulianotti \\ Loughborough University, Leicestershire, United Kingdom
}

\begin{abstract}
Resumo
Recentemente, uma ampla variedade de organizações (notadamente a ONU e organizações não-governamentais) tem usado o esporte como uma ferramenta de intervenção para a pacificação. Este artigo examina e teoriza sobre essas iniciativas através da expansão do setor de "esporte para o desenvolvimento e a paz" (EDP). Para iniciá-lo, foram localizados projetos de EDP dentro de seus contextos históricos, como elementos significativos dentro da "sociedade civil global" emergente. Posteriormente, delimitou-se três modelos de tipos-ideais de projetos em EDP: "técnico", "dialógico" e "crítico". Cada modelo é examinado através de um conjunto comum de heurísticas sociais, tais como seus objetivos centrais e métodos paradigmáticos. O modelo pode ser empregado para analisar outros campos de pacificação e desenvolvimento. Os dois primeiros modelos são mais influentes entre os projetos de EDP existentes; os benefícios potenciais do modelo "crítico" são também delineados.
\end{abstract}

Palavras-chave: Esporte. Desenvolvimento e Paz. Pacificação. Sociedade Civil Global.

\section{Introdução}

$\mathrm{E}$ sportes modernos relacionam-se duplamente com conflitos nacionais ou étnicos. Primeiramente, o esporte tem sido associado às fortes manifestações de um violento nacionalismo e militarismo, por exemplo, durante o Império Britânico, na Alemanha nazista ou na Guerra Fria, envolvendo os EUA e a antiga URSS (BROHM, 1987;

1-Esta é uma versão revisada de artigo publicado em língua inglesa na Ethnic and Racial Studies, vol. 34, n. 2, p. 207-228, 2010. A pesquisa desse artigo foi financiada pela Fundação Nuffield. Traduzido com autorização do autor pelo Centro de Excelência Empresarial LtdaMe (Cetur). Revisão: Cleber Dias. 
MANGAN, 1985). O esporte também tem sido visto como uma causa ou foco de grandes conflitos sociais, como nos Bálcãs entre sérvios e croatas, na Irlanda do Norte entre unionistas protestantes e católicos irlandeses, ou na 'guerra do futebol' entre Honduras e El Salvador. Em segundo lugar e em forte contraste, federações importantes do esporte, como o Comitê Olímpico Internacional (COI), afirmam que os esportes e grandes eventos esportivos ajudam a promover contatos, amizades, paz internacional e entendimento entre povos diferentes (GUTTMANN, p. 28, 2002).

Nos últimos anos, esta segunda abordagem tem encontrado uma nova maneira de se manifestar, na forma do setor de "esporte para o desenvolvimento e paz" (EDP). O setor EDP usa o esporte como ferramenta de intervenção social, a fim de promover o desenvolvimento e a paz, principalmente em países em desenvolvimento ou em regiões abaladas pela guerra. A Organização das Nações Unidas tem desempenhado um papel fundamental na promoção do trabalho de EDP, ajudando a estabelecer o Grupo de Trabalho Internacional sobre EDP (em inglês, SDP IWG, 2008); tornando o ano de 2005 o Ano Internacional do Esporte e Educação Física, com a paz e o desenvolvimento entre os princípios axiais (Assembleia Geral da ONU de 2006); e pelo estabelecimento de um escritório (o UNOSDP), que é dedicado ao setor EDP.

Muito do trabalho do EDP é realizado no "Sul Global" por diferentes tipos de organizações localizadas no "Norte Global". Organizações importantes do setor de EDP incluem as federações esportivas internacionais, organizações não-governamentais (ONGs), os Estados-Nação, organizações intergovernamentais (incluindo a ONU), as multinacionais, organizações comunitárias e os novos movimentos sociais. $\mathrm{O}$ trabalho realizado por organizações de EDP inclui: educação e promoção da saúde; iniciativas anti-racismo, promoção da igualdade de gênero e direitos e oportunidades para pessoas com deficiência; iniciativas contra o crime, reconciliações, diálogo e reconstrução de regiões devastadas pela guerra. Nos últimos anos, os cientistas sociais têm contribuído fortemente em pesquisas no setor de EDP. Por exemplo, o trabalho de Armstrong $(2004,2007)$ na Libéria, Keim (2003) em seus trabalhos sobre EDP na África do Sul, os estudos de Darnell (2008) em uma agência de desenvolvimento canadense, a discussão de Gasser e Levinsen (2004) sobre uma ONG dedicada ao EDP na Bósnia e o trabalho de Schulenkorf (2010) no Sri Lanka. 
Sendo assim, pretendo aprofundar esses trabalhos através da elaboração de um modelo social científico do setor de EDP. Esse artigo é em grande parte teórico, mas reflete minha pesquisa no setor de EDP realizada com vários funcionários e projetos na região dos Bálcãs, na Alemanha, Oriente Médio, Sul da Ásia e na Suíça. Também realizei trabalhos de consultoria em projetos de EDP no Oriente Médio, Sul da Ásia e na Europa, e tenho participado e dado palestras como convidado em muitas conferências e simpósios sobre EDP em todo o mundo.

Meu argumento aqui é separado em duas partes principais. Na primeira parte, discuto o contexto do esporte mundial do setor EDP, relacionado à história e à política. Em termos históricos, o setor EDP é a última fase na formação do esporte global. Em termos políticos, vejo o setor EDP como um aspecto importante da 'sociedade civil global'. Na segunda parte, apresento um modelo tridimensional do setor EDP, com foco específico nas atividades realizadas na área de construção da paz e resolução de conflitos.

\section{Primeira Parte - Esporte no mundo: história e política}

a) Contexto Histórico

No que tange ao desenvolvimento do esporte mundial em termos históricos, e especificamente, às relações entre o Norte e o Sul Global, nota-se a existência de três principais estágios históricos neste processo. Esses estágios não são totalmente separados uns dos outros, o que significa que diferentes tendências encontradas no primeiro e no segundo estágio podem também ser encontradas no terceiro.

i) Estágio 1 - Esporte Global 1.0: Esporte como uma Força de Colonização e 'Civilização' (final do século XVIII até os meados do século XX).

Este estágio dura desde o final do século XVIII até os meados do século XX. Durante este período, o esporte se espalhou quando os países europeus estavam colonizando o mundo. Os britânicos davam grande importância ao esporte, assim muitos esportes daquela nação se difundiram através das colônias e também através das rotas de comércio (HOLT, 1989; MANGAN, 1985). Ao mesmo tempo, os esportes britânicos eram 
usados como força "civilizadora", o que resultou na supressão das "culturas corporais" indígenas entre os povos colonizados (BALE \& SANG, 1996). As associações de futebol se difundiram internacionalmente, principalmente por trabalhadores britânicos nas áreas de educação, indústria e comércio (LANFRANCHI et al, 2004; MASON, 1995). O baseball foi difundindo de forma "neocolonial", em territórios sujeitos à hegemonia ou influência norte-americana, como a América Central e o Leste Asiático (GUTTMANN, 1994).

ii) Estágio 2 - Esporte Global 2.0: Esporte, Nacionalismo, PósColonialismo e Desenvolvimento (1940 a 1990)

Fase entre 1940 até 1990, num momento em que as lutas nacionalistas e pós-coloniais existiam por várias partes do Sul Global. No Caribe, o cricket ajudou a simbolizar a luta de libertação dos afro-caribenhos, principalmente através de vitórias épicas contra o velho senhor colonial, a Inglaterra (BECKLES \& STODDART, 1995; JAMES, 1963). Nações africanas independentes desempenharam um papel crucial na promoção de um boicote internacional nas relações esportivas com o regime segregacionista da África do Sul a partir de 1960, e este trabalho se tornou fundamental à estratégia do movimento anti-Apartheid (BOOTH, 1998). Após a independência, o esporte foi usado por muitas nações do "Terceiro Mundo" como um caminho para pertencer à sociedade internacional, de modo que, por exemplo, o número total de países membros no corpo gestor do futebol (FIFA) cresceu de 54 para 149, entre 1945 e 1980 (GOLDBLATT, 2003). Os órgãos esportivos gradualmente começaram a refletir as políticas de modernização do FMI e do Banco Mundial, priorizando assim mais modernização e desenvolvimento do esporte nos países em desenvolvimento. Tais países receberam mais apoio financeiro para projetos ligados ao desenvolvimento do esporte, de modo que estas nações obtiveram mais influência política dentro do esporte, desempenhando uma função crucial no apoio à ascensão de João Havelange na FIFA para se tornar presidente em 1974. 
iii) Estágio 3 - Esporte Global 3.0: Esporte, Desenvolvimento e Paz (meados da década de 1990 - presente)

Este estágio começa em meados dos anos 90 e continua até hoje. Neste tempo, os principais temas dos outros estágios - colonialismo, nacionalismo, pós-colonialismo e o desenvolvimento do esporte - continuaram a se destacar dentro do esporte. Mas durante esta fase, o tema do esporte para o desenvolvimento se estabeleceu. Podemos também identificar dois sub-estágios ou períodos específicos durante esse estágio, que é mais abrangente:

Sub-estágio 3.1 do Esporte Global (1995-2005): Este primeiro período vai desde a expansão súbita do movimento EDP e incluiu até a colaboração da ONU em 2005. Muitos projetos EDP foram criados durante esse período, mas tinham fraca coordenação internacional, sustentabilidade ou reflexão crítica sobre seus trabalhos.

Sub-estágio 3.2 do Esporte Global (2005 até o presente): Este segundo período mostra uma versão mais madura do setor EDP, existindo uma coordenação mais forte, rede de relacionamento e reflexão crítica. As agências EDP são hoje mais eficientes na obtenção de apoio financeiro de várias fontes, sejam elas governos, multinacionais, doadores privados ou federações esportivas. Além disso, existe atualmente o crescimento de eficazes instituições transacionais EDP - como a plataforma Sport and Development na Suíça, Peace and Sport em Mônaco, Right to Play em Toronto e Sreetfootballworld em Berlim.

b) Contexto Político

Nesse contexto, interpreta-se o setor EDP como uma parte da "sociedade civil global" (ANHEIER, KALDOR \& GLASIUS, 2007; CHANDLER, 2005; KALDOR, 2003; KEANE, 2003). Existem dois aspectos que precisam ser observados sobre a sociedade civil global desde o princípio. Primeiro, a sociedade civil global tende a ser associada com a promoção de uma mistura de desenvolvimento, paz e justiça social, particularmente no Sul Global. As instituições-chave na sociedade civil global são as agências de desenvolvimento, entre elas 
as ONGs e diversas agências da ONU. Segundo, como Kaldor (2003) argumentou, a sociedade civil global não é um espaço político livre. Em vez disso, é uma arena complexa, na qual diferentes indivíduos, grupos e instituições buscam mostrar suas próprias visões do que a sociedade civil global deve ser, ao entrar em diversos tipos de lutas, parcerias e interdependência.

Existem quatro forças principais dentro da sociedade civil global. Cada uma dessas forças é relevante ao setor EDP:

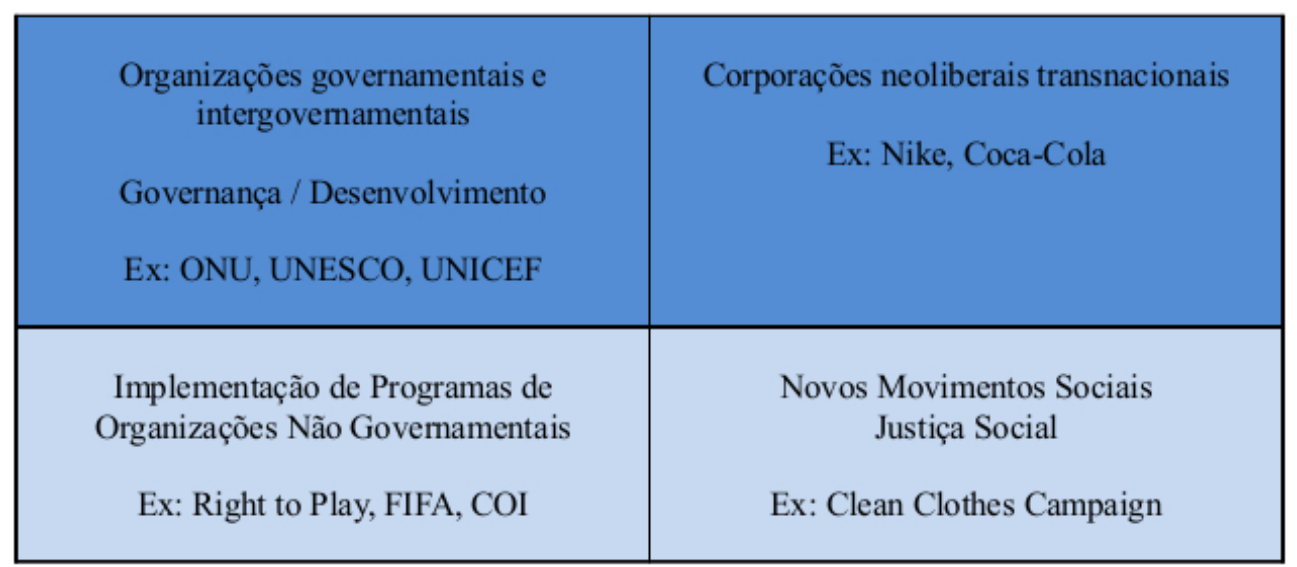

Quadro 1: Instituições de EDP na sociedade civil global

i) Primeiramente, existem instituições governamentais nacionais e internacionais, incluindo os Estados-Nação, organizações intergovernamentais, como a ONU e a União Européia; várias agências da ONU, como a UNESCO e a UNHCR [Agência da ONU para Refugiados], Banco Mundial e FMI. Muitas dessas instituições têm seus próprios escritórios para o EDP, ou oferecem apoio financeiro e logístico para projetos sobre $\mathrm{EDP}^{2}$.

ii) Em segundo lugar, o setor privado, principalmente as multinacionais, que financiam projetos EDP ou usam programas de "responsabilidade social" para realizarem seus próprios projetos relacionados ao esporte.

iii) Terceiro, as tradicionais instituições da sociedade civil, como as organizações não-governamentais (ONGs). Estas incluem agências exclusivas para esportes, tais como a Right to Play e ONGs que oferecem atividades esportivas, como World Vision ou a Amnesty International. Além de federações internacio- 
nais esportivas, como o COI ou a FIFA que administram ou patrocinam projetos EDP.

iv) Novos movimentos sociais (NMSs) são as organizações mais radicais dentro da sociedade civil global, principalmente aquelas que buscam justiça social e denunciam abusos aos direitos humanos pelas grandes multinacionais e governos nacionais. Os NMSs que realizam atividades de EDP denunciam abusos aos direitos humanos em fábricas de mercadorias esportivas, e também protestam contra as relações entre as instituições esportivas e as elites corruptas ou opressivas.

Obviamente, várias agências e projetos EDP são de diferentes portes e tamanhos. Algumas ONGs têm crescido a nível multinacional, enquanto outras focalizam mais as comunidades e o local. Podem também haver inter-relações complexas entre as instituições que pertencem a categorias diferentes. Por exemplo, empresas privadas podem trabalhar com as agências intergovernamentais e financiar ONGs a fim de realizar atividades de EDP dentro de certas regiões, embora muitos funcionários de ONGs já trabalharam em NMSs anteriormente.

\section{Parte Dois - Setor de EDP: três tipos de agência de pacificação}

Com vistas a delinear e explorar um modelo tridimensional de projetos EDP, este artigo concentrou-se especificamente nas agências de pacificação, uma vez que a pacificação é provavelmente o tema mais substancial dos projetos de EDP, sendo o foco principal do projeto em questão.

Os três diferentes tipos de projetos EDP são os Técnicos, Dialógicos e Críticos. Os três são "tipos ideais" de acordo com a percepção de Max Weber sobre o termo ${ }^{3}$. Os tipos ideais permitem "distinções

2-Veja por exemplo, http://www.unicef.org/sports/; e http://www.pch.gc.ca/pgm/aiia/si-is/ssdp-sdp/index-eng.cfm.

3-Um tipo ideal é "composto pela acentuação unilateral de um ou mais pontos de vista e pela síntese de um grande fenômeno individual concreto difuso, discreto, mais ou menos presente e, ocasionalmente, ausente, que são organizados de acordo com os pontos de vista unilateralmente enfatizados em uma construção analítica unificada" (WEBER, p. 90, 1949). 
sociológicas sutis" a serem estabelecidas entre as abstrações e descobertas empíricas, ou entre os tipos ideais de si próprios (WEBER, 1978, p. 23-4). Entretanto, concordo que diferenças podem surgir entre os tipos ideais e suas manifestações reais.

As principais características dos três tipos ideais são definidas na Quadro 2.

\begin{tabular}{|c|c|c|c|}
\hline $\begin{array}{c}\text { Características } \\
\text { definidoras }\end{array}$ & Técnico & Dialógico & Crítico \\
\hline Objetivo & Resolução de problemas & Novas Relações Sociais & Transformações sociais \\
\hline Temas-chave & $\begin{array}{l}\text { Intervenção e } \\
\text { mensuração de } \\
\text { resultados }\end{array}$ & $\begin{array}{l}\text { Diálogo e Novos } \\
\text { Significados }\end{array}$ & Andragogia e Novas \\
\hline Estrutura administrativa & Hierarquia & Árbitro / Lider & Horizontal / Fluida \\
\hline Grupos de usuários & $\begin{array}{l}\text { Unidades Sociais } \\
\text { Especificadas }\end{array}$ & $\begin{array}{l}\text { Grupos Comunitários } \\
\text { especificados }\end{array}$ & $\begin{array}{l}\text { Diversos grupos } \\
\text { comunitários }\end{array}$ \\
\hline Métodos & Clínicas agendadas & Formação de formadores & $\begin{array}{l}\text { Acampamentos, } \\
\text { Intercâmbios }\end{array}$ \\
\hline Ferramentas & Esportes convencionais & Esportes modificados & $\begin{array}{l}\text { Novos jogos / Outras } \\
\text { práticas culturais } \\
\text { comunitárias }\end{array}$ \\
\hline $\begin{array}{l}\text { Relações Sociais com } \\
\text { Clientes }\end{array}$ & Competitiva & Cooperativa & Comunitária \\
\hline Relações com doares & Regulação & Correspondência & Autonomia \\
\hline $\begin{array}{c}\text { Relações com a } \\
\text { sociedade civil global }\end{array}$ & Instrumental & Estratégica & Complementar \\
\hline $\begin{array}{l}\text { Monitoramente e } \\
\text { avaliação }\end{array}$ & $\begin{array}{l}\text { Positivista; Registro } \\
\text { sistemático; Medição }\end{array}$ & $\begin{array}{l}\text { Métodos Múltiplos / } \\
\text { Participativos }\end{array}$ & $\begin{array}{l}\text { Participativos, } \\
\text { complementares e crítico } \\
\text { reflexivos }\end{array}$ \\
\hline
\end{tabular}

Quadro 2: Três tipos de projetos EDP na sociedade civil global

a) Projetos técnicos de EDP

O projeto técnico EDP possui uma filosofia positivista "realista", pressupondo que certas sociedades encontram problemas sociais, objetivamente identificáveis e "reais". Os funcionários dos projetos técnicos EDP acreditam que, em situações de conflito, se encontram bem preparados para oferecer uma análise imparcial dos problemas e para identificar e implementar estratégias para resolver tais problemas. As agências técnicas EDP preferem atuar por meio de estratégias de intervenção diretas. 
As agências técnicas estabelecem metas específicas e mensuráveis para seus projetos, que devem ser cumpridas dentro de prazos especificados. A eficácia dos projetos EDP é avaliada através de uma mensuração "objetiva" dos resultados. As agências EDP monitoram e avaliam os projetos através de técnicas positivistas, como a compilação de dados quantitativos e mensuração dos resultados de intervenção. Existem opiniões divergentes no setor EDP sobre os benefícios do uso de medidas positivistas do impacto do projeto. No entanto, a maioria daqueles que trabalham com EDP apoiam a ideia de que a eficácia dos projetos passa por algum tipo de avaliação. Um funcionário EDP no Oriente Médio afirmou que, "tinha que acontecer. Muitos projetos no passado foram iniciados diante da grande empolgação em torno do esporte para o desenvolvimento, mas simplesmente não se pensava sobre sustentabilidade. Nós precisávamos saber o que funcionava e como sustentá-lo e estamos agora caminhando nesta direção". No passado, as atividades de EDP foram várias vezes criticadas por serem um "exercício de relações públicas" para ganhar publicidade, mas com pouco efeito real. Esta crítica é recusada pelo uso eficaz de atividades de acompanhamento e avaliação para testar o impacto das intervenções de EDP.

As agências técnicas de EDP tendem a usar esportes estabelecidos, que detêm aspectos competitivos. As agências técnicas trabalham dentro de contextos específicos, como definido no tempo e espaço, e com grupos sociais específicos, o que pode ser definido por residência, sexo ou idade. Estas agências tendem a oferecer clínicas que funcionam em horários específicos. Os funcionários de EDP desempenham um papel fundamental na organização e estruturação das atividades dos participantes durante o funcionamento dessas clínicas.

As agências técnicas tendem a ver o setor de EDP como uma entidade hierárquica, principalmente em termos políticos e geográficos, de modo que as instituições internacionais estão no topo, passando instruções, experiência e conhecimento para grupos de usuários. Isto significa que "especialistas" em EDP estão repassando conhecimentos de EDP em um processo de mão única, ao invés de compartilhar métodos e conhecimentos.

Historicamente, as agências técnicas de EDP eram mais evidentes durante o sub-estágio 3.1 do esporte global, principalmente durante o final dos anos 1990 e início de 2000. Naquela época, as ONGs ou federações esportivas tinham experiência e conhecimento relativamente 
limitados para realizar um tipo de trabalho de EDP em contextos locais. É também possível notar algumas ligações comuns entre a maneira que as agências técnicas de EDP operam e a antiga estratégia colonial do estágio global do esporte 1.0. Estas agências tendem a se dirigir às áreas "problema" tentando corrigi-los, embora o diálogo com grupos de usuários seja fraco.

O modelo técnico está associado com relações da sociedade civil global. Agências de EDP reconhecem que estas relações serão regulamentadas por doadores que querem intervir nos objetivos do projeto e nos métodos de avaliação. As agências técnicas preferem ter relações instrumentais com outras instituições da sociedade civil global, muitas vezes as ONGs, para realizar trabalhos mutuamente benéficos.

Muitas agências técnicas de EDP possuem "relações públicas" ou perfil de mídia relativamente forte. As maiores agências técnicas de EDP possuem excelentes conexões sociais (ou "capital social") com grupos de elite. Elas são capazes de ganhar o apoio e endosso de celebridades internacionais e isso ajuda a atrair o interesse do setor empresarial. Grandes corporações, geralmente veem o envolvimento com atividades de EDP em termos instrumentais somente, como uma maneira de estender seus perfis de mercado. Por exemplo, a Nike interpreta "responsabilidade social" como um "impulsionador de crescimento", como "parte de um modelo de negócios saudável" que "cria uma vantagem competitiva"4.

Algumas federações esportivas também veem suas atividades de EDP vinculadas ao desenvolvimento do esporte a nível internacional, principalmente em partes do mundo onde o esporte não é bem conhecido $^{5}$. Essas federações utilizam clínicas de EDP para promover o esporte, proporcionando sessões de treinamento de habilidades básicas do jogo e também requisitando que clínicas de EDP pratiquem o es-

4-Veja http://www.nikebiz.com/responsibility/.

5-Ao contrário de agências técnicas, algumas ONGs cruciais no setor de EDP mostram prudência ao trabalhar com as organizações de desenvolvimento esportivo com pouco interesse no trabalho de EDP. De acordo com a afirmação de um funcionário: "Não reconhecíamos como membro uma academia esportiva genuína, como muitas das que agora estão sendo criadas na África e em outros lugares, onde fazem acreditar que estão realizando algo positivo no aspecto social, mas na realidade querem mesmo é alimentar a máquina de talentos. Isso é algo que nós nunca iríamos apoiar".

Pensar a Prática, Goiânia, v. 15, n. 3, p. 551-820, jul./set. 2012 
porte mantendo plenamente suas características competitivas. Desta forma, a federação esportiva pode usar o projeto EDP em atividades na mídia para mostrar a natureza de "construção da paz" do esporte. Um dos problemas é que esses esportes não são bem conhecidos, tendo menos chances do que esportes populares de se tornarem ferramentas eficazes intervencionistas, principalmente quando o equipamento esportivo é danificado e não é substituído.

Algumas agências técnicas têm sido criticadas pela forma como operam - por exemplo, administrando clínicas de treinamento através de uma fórmula já estabelecida ao invés de ser flexível de acordo com as circunstâncias locais; por serem muito estritas ao selecionar participantes do projeto, de acordo com critérios pré-determinados (por exemplo, porcentagem de gênero ou idade) e por sua falta de sensibilidade à complexidade da cultura local. De acordo com relato de um funcionário de uma importante ONG durante trabalho de campo, essas agências tendem a "chegar num lugar distante, armados com seus manuais de treinamento e equipamento estranho, para ensinar 'as crianças da guerra' como jogar de verdade".

O modelo técnico, de certa forma, é direcionado aos contextos de mercado, principalmente no trabalho com empresas ou organizações governamentais voltadas ao mercado. Os doadores estão mais propensos a ter pouca experiência em zonas específicas, preferindo resultados demonstráveis em curto prazo. Os projetos tendem a ser implementados por ONGs com experiência prévia em EDP, com bom capital social entre os doadores em potencial e uma vontade de competir por contratos em "mercados" em desenvolvimento.

\section{b) Projetos dialógicos de EDP}

O tipo "dialógico" de agência EDP possui uma abordagem comunicativa e interpretativa. As agências dialógicas sabem que a guerra ou conflitos violentos são resultado de relações tensas entre as diferentes comunidades. Esses conflitos são intensificados pela falta de contato social, confiança e mediação eficaz entre as duas comunidades. A abordagem dialógica acredita que as agências de EDP podem ajudar a construir uma ponte entre as duas comunidades para promover um contato significativo entre os povos divididos.

Desta forma, as abordagens dialógicas procuram fornecer novas bases para as relações entre as partes divididas. Agências de EDP ten- 
tam estabelecer novos significados entre as partes divididas, como uma forma de pedagogia que se envolve com e ensina a grupos de usuários. Os princípios dialógicos de muitos projetos para a construção da paz, particularmente no Oriente Médio, nos Bálcãs e no sul asiático, são fazer com que os participantes entrem mais em contato com outras comunidades, ajudando a mudar a percepção do outro através das relações esportivas de cooperação.

A agência dialógica de EDP é um mediador independente, porém decisivo quando mal-entendidos, desavenças ou outros conflitos surgem. Em alguns projetos, por exemplo, durante o jogo, empregam-se trabalhadores locais como mediadores ou árbitros para resolver disputas. As partes em conflito são consultadas, mas é a agência de EDP que toma a frente quando as discordâncias continuam, e assim toma as decisões.

A agência dialógica de EDP se esforça para assegurar a participação de grupos sociais específicos dentro das diferentes comunidades. Ao contrário da agência técnica de EDP, a dialógica permite que grupos de usuários entrem e saiam dos projetos EDP em diferentes momentos.

O projeto dialógico de EDP está disposto a mudar os esportes já existentes, para adaptar as metas inclusivas do programa de EDP. Os projetos dialógicos de EDP utilizam equipes mistas nos esportes e constroem capital social inclusivo através das comunidades, pelo estabelecimento de relações baseadas na cooperação informal e prática. Os esportes são organizados de forma a promover a participação integradas comunidades, de modo que as relações de cooperação ocorram entre os grupos divididos. Por exemplo, em esportes como futebol, a inclusão social de meninas é promovida pela "contagem dobrada" da pontuação destas. Muitos projetos também garantem que esportes de equipe sejam misturados entre as comunidades e as divisões.

O método comum é a técnica de formação de instrutores, no qual a agência de EDP treina voluntários locais de acordo com métodos e valores do programa. Os participantes assim retornam às suas comunidades para treinar mais voluntários. A técnica de formação de instrutores é comum entre grandes e pequenas ONGs que operam, por exemplo, nos Bálcãs e no Oriente Médio. Esses projetos permitem aos "instrutores treinados" escolherem como implementar esses métodos. De acordo com explicação de um funcionário de EDP no Oriente Médio, "nós treinamos cerca de quarenta pessoas neste projeto e quando estes vão 
para casa e treinam mais pessoas, o treinamento pode atingir mais de mil pessoas rapidamente. Mas eles sabem a melhor forma de implementar o projeto em casa, eles conhecem povo local, o que é necessário, e os esportes que irão se encaixar".

A agência dialógica de EDP tende a monitorar e avaliar seu trabalho usando vários métodos, especificamente as técnicas participativas qualitativas que engajam ativamente grupos de usuários. Exemplos de métodos mistos incluem os qualitativos (por exemplo, vídeo-gravação de entrevistas dos participantes e técnicas de contar histórias) e quantitativos (como dados demográficos dos grupos de usuários).

A agência dialógica de EDP busca estabelecer uma forte relação com aqueles que a apoiam ou seus doadores. As agências dialógicas tendem a manter um relacionamento próximo às ONGs de desenvolvimento e organizações intergovernamentais por toda a sociedade civil global. Em outras palavras, essas instituições da sociedade civil global tendem a usar a abordagem dialógica nas atividades de EDP, devido a considerável experiência na realização de trabalhos básicos de EDP. Grandes ONGs internacionais também usam a abordagem dialógica na construção de parcerias com pequenas agências locais de EDP. O capital social local é também importante para o desenvolvimento de projetos, que terão efeitos nas comunidades locais. Algumas das grandes ONGs são suportadas financeiramente por federações desportivas, mas essas ONGs são capazes de usar diferentes modalidades esportivas em suas sessões de projeto. No geral, as agências dialógicas de EDP procuram estabelecer relações estratégicas com outras instituições a fim de garantir uma forte cooperação e parcerias de longo prazo.

A agência dialógica de EDP tem se destacado neste setor desde o início dos anos 2000, uma vez que a sustentabilidade dos projetos tornou-se mais importante. A agência dialógica de EDP também tem paralelos com o estágio do Esporte Global 2.0, uma vez que permite que as diferentes sociedades mostrem criatividade e singularidade, mas são as instituições do Norte Global que estão de fato no controle.

\section{c) Projetos críticos de EDP}

O projeto crítico de EDP é baseado em uma abordagem altamente reflexiva e crítica em relação às atividades de EDP. Os projetos críticos de EDP tentam assegurar dois tipos de transformações: nas relações entre comunidades divididas e na forma que o trabalho de EDP é 
conduzido.

Os projetos críticos de EDP acreditam que as experiências de aprendizagem de longo prazo e reflexões de diferentes "alunos" são fundamentais para se estabelecer uma paz duradoura. Esses projetos promovem a apropriação local dos projetos, com a participação total dos grupos locais no planejamento e gestão dos programas de EDP. Os projetos sabem que as comunidades locais sabem identificar suas necessidades para justificarem seus conflitos e para encontrar as melhores estratégias e soluções. Funcionários que trabalham para projetos críticos de EDP estão também numa sólida posição para estender a história e a complexidade social de conflitos individuais.

Historicamente, a abordagem crítica é associada aos aspectos mais progressistas dos estágios de Esporte Global 2.0 e 3.0. A agência crítica de EDP é aqui vista como uma instituição iluminada e internacionalista, que promove a autonomia de auto-realização e habilidades criativas dos grupos de usuários.

A principal função das agências críticas de EDP é construir confiança, comunicação e interesses comuns, como uma forma de obter uma profunda transformação entre as comunidades. Assim, por exemplo, muitas ONGs pequenas relatam a função de facilitar o processo de paz local, em parte, permitindo que grupos de usuários esclareçam suas necessidades e para que entendam a propriedade local do projeto.

Existe um tipo de comunicação e educação "andragógica" de comunicação entre grupos de usuários e funcionários de EDP. A andragogia permite que alunos independentes assumam responsabilidades decisórias e possui um forte impacto quando os "alunos" aprendem através da experiência, reconhecendo assim os erros ou problemas ao longo do caminho (KNOWLES, 1984). As agências críticas de EDP usam os princípios andragógicos para estabelecer novas comunidades que se baseiam na plena participação de grupos de usuários. Apesar de termos como andragogia não serem usados explicitamente, várias ONGs têm demonstrado seguir este princípio, aproveitando a experiência de grupos de usuários para reformular suas estratégias e métodos. Por exemplo, em locais como Sri Lanka e na África Ocidental, algumas ONGs locais, comprometidas com a paz, começaram a usar o esporte nestas atividades, a pedidos dos membros da comunidade local.

As agências críticas de EDP trabalham com uma grande variedade de grupos comunitários; não apenas jovens, mas também os pais, fa- 
mílias, amigos, anciões dos vilarejos e assim por diante, que estão todos aptos a contribuir para o sucesso do projeto. Essas agências também difundem e administram as relações sociais entre grupos das comunidades divididas, assim os participantes de projetos EDP se envolvem com "outros" grupos sociais. As agências críticas olham além das relações esportivas, contribuindo para o desenvolvimento das relações sociais comunitárias entre os povos divididos.

As agências críticas de EDP são bastante criativas na concepção e implementação de projetos. Esses projetos criam novos jogos com características distintas da construção de uma comunidade, desprovidas da bagagem cultural de esportes estabelecidos. Esses esportes podem ser abordados igualmente por todos os participantes. Os esportes podem ser misturados com muitas outras práticas culturais para promover o contato entre as comunidades. Os projetos críticos de EDP às vezes promovem intercâmbios, onde os participantes e suas comunidades vizinhas recebem, calorosamente, convidados do "outro" lado. Esses projetos geralmente realizam acampamentos, onde os participantes de diferentes comunidades se reúnem e se integram em espaços neutros durante vários dias; depois disso, os participantes voltam para casa e compartilham suas experiências com suas comunidades.

Por exemplo, projetos no Sri Lanka são particularmente eficazes no emprego de métodos intercomunitários e acampamentos realizados em locais neutros. Os acampamentos oferecem uma variedade de atividades integradas de ensino, incluindo artes, artesanato, dança, teatro, música e a realização de novos jogos com equipes etnicamente misturadas. Os intercâmbios dos alunos após os acampamentos são organizados com forte apoio e hospitalidade por parte dos pais, dos anciãos da aldeia e das comunidades maiores. Algumas aldeias realizam grandes festivais para celebrar essas visitas.

As agências críticas de EDP tentam explicar aos doadores potenciais a estratégia holística e a utilidade de longo prazo de suas atividades dentro de contextos específicos. Essas agências se comprometeram a manter autonomia sobre os doadores quanto aos princípios e objetivos dos projetos de EDP. Alguns funcionários de ONGs relataram que enfrentam dificuldades para convencer os doadores que a eficácia dos projetos é difícil de ser medida porque o objetivo é ter um impacto de longo prazo e difuso. Algumas agências dizem que preferiam os vínculos com fundações privadas, onde relações pessoais diretas podiam ser estabelecidas e onde era mais fácil explicar a 
visão holística e de longo prazo dos trabalhos de EDP. As agências críticas de EDP também são mais propensas a se envolverem com novos movimentos sociais que destacam as questões de justiça social, que podem ser abordadas na implementação e avaliação dos projetos.

As agências críticas de EDP procuram estabelecer seus trabalhos no âmbito das atividades de instituições da sociedade civil global maiores, dentro de um contexto específico. De acordo com um funcionário de uma pequena agência europeia, "você tem que olhar para as arquiteturas de paz global e assim você tem que desempenhar certo papel. Existem muitos agentes e você não pode desempenhar todos os papéis, não faz sentido... Você tem que discutir a sua função, caso contrário você não contribui".

Agências críticas de EDP utilizam métodos de acompanhamento e avaliação participativos, complementares e criticamente reflexivos. Como a abordagem dialógica, as agências críticas de EDP usam métodos diversos e participativos para uma maior participação do usuário. No entanto, essas agências vão mais longe, uma vez que usam técnicas andragógicas para melhorar suas próprias práticas profissionais, para que o projeto esteja sempre aberto a novas ideias e novas práticas.

\section{Conclusão: estágio do esporte global 3.3}

O esporte tem um relacionamento de longo prazo e de vários estágios com o desenvolvimento da sociedade global. O crescente setor de EDP é uma parte crucial dessa relação e está também no seio da sociedade civil global.

Neste artigo, apresentou-se, portanto, um modelo tridimensional do setor EDP. Os projetos de EDP precisam ser entendidos dentro de seu contexto histórico, através de um foco no "esporte global" e sua configuração política, com referência à sociedade civil global. As três abordagens de EDP aqui discutidas são vinculadas aos seguintes contextos: projetos técnicos de EDP favorecem instituições no Norte Global voltadas ao mercado e possuem alguns paralelos com estratégias coloniais na resolução de problemas, como no estágio de esporte global 1.0; os projetos dialógicos de EDP são mais evidentes entre as organizações intergovernamentais e as ONGs em rede e esta abordagem é vinculada ao início da fase pós-colonial de modernização "independente"; a abordagem crítica de EDP é presente entre ONGs inovadoras e de pequeno porte, vinculadas às estratégias de auto-governo e auto-empo- 
deramento no estágio avançado de "desenvolvimento através do esporte". É possível utilizar este modelo para analisar outros tipos de desenvolvimento e trabalhos de pacificação dentro da sociedade civil global.

De fato, a maioria dos projetos de EDP apresenta uma mistura dos métodos técnicos, dialógicos e críticos. Em termos de projetos técnicos, o objetivo de muitos projetos EDP é a resolução de problemas, possuindo unidades sociais específicas para realizar as atividades, fortes abordagens intervencionistas, utilização de relações instrumentais com toda a sociedade civil global e emprego de métodos positivistas no monitoramento e avaliação. Em termos de projetos dialógicos, os projetos de EDP utilizam métodos de "formação dos instrutores", esportes modificados, relacionamentos integrados e de cooperação com grupos de usuários e uma diversidade de métodos de monitoramento e avaliação. A abordagem crítica é menos óbvia entre projetos de EDP, mas algumas características incluem o papel de facilitador, acampamentos, intercâmbio de alunos e métodos de propagar o jogo.

Existem parcerias complexas entre os diferentes tipos de agências de EDP. Por exemplo, uma ONG de EDP dinâmica tem uma forte parceria com uma federação esportiva totalmente focada no comércio, com os departamentos de desenvolvimento do governo nacional e com doadores privados liberais. Podem surgir conflitos entre estas parcerias, por exemplo, quando a instituição financiadora tenta influenciar a forma como a agência de EDP deve funcionar ao escolher seus grupos de clientes.

Usou-se aqui o conceito de sociedade civil global para inserir o setor de EDP dentro de um contexto político mais amplo. Dentro do setor de EDP, as instituições mais influentes são as multinacionais e outras empresas, organizações governamentais nacionais e internacionais e ONGs, que possuem uma abordagem pragmática de trabalho, utilizando uma mistura dos métodos técnicos e dialógicos. Politicamente, isso significa que a maioria dos trabalhos de EDP focaliza "objetivos seguros", tais como suprir necessidades humanas básicas ou envolver-se com os 'Objetivos de Desenvolvimento do Milênio', ao invés de cumprir com metas mais desafiadoras, como uma maior justiça social.

No futuro, o campo de EDP se beneficiaria ao se direcionar ao "estágio de esporte global 3.3". Em suma, esta fase incluiria a abordagem crítica ao trabalho de EDP de uma forma muito mais ampla, focalizando muito mais em questões de justiça social. 
Para atingir o estágio Global do Esporte 3.3, várias mudanças precisam ocorrer. Em primeiro lugar, os projetos de EDP precisam se tornar mais críticos, com maior entendimento das necessidades da comunidade e mais abertos a oportunizar ações próprias. As agências de EDP também precisam estabelecer relações mais igualitárias com os seus grupos de usuários. As agências de EDP também precisam trabalhar mais com novos movimentos sociais e ONGs relativamente radicais, particularmente as instituições do Sul Global que possuem forte vínculo com a população local. Segundo, as agências SDP devem investigar como podem se transformar criticamente. Este é um aspecto do trabalho andragógico que pode ser usado muito mais substancialmente. Terceiro, agências de pacificação de EDP devem construir relacionamentos de longo prazo com fortes instituições doadoras, especialmente as organizações intergovernamentais, para realizar trabalho de longo prazo sem a distração de metas de curto prazo ou prazos para "resultados". Finalmente, agências de EDP precisam encontrar maneiras de permitir que as comunidades definam suas necessidades e metas estabelecidas para diferentes projetos.

A passagem para o estágio global do esporte 3.3 é uma possibilidade de longo prazo para área de EDP e coloca o modelo crítico no centro do seu trabalho. O estágio 3.3 pode chegar a realizar projetos EDP mais dispendiosos, em parte devido ao tempo necessário para realizar o diálogo preliminar com grupos de usuários, que pode ser demorado. No entanto, a abordagem crítica dentro do Estágio Global 3.3 permitiria que as agências de EDP tivessem estratégias práticas e normativas mais robustas, para a construção de comunidades resistentes e pacíficas em contextos de conflitos étnicos, raciais ou nacionalistas. Seria um registro da transição progressiva na interface histórica da sociedade do esporte global. Seria também permitir que a pacificação do setor de EDP mapeasse um caminho que outras agências da sociedade civil global podem seguir.

The Sport, Development and Peace Sector: A Sociological Model of Peacemaking Agencies

\begin{abstract}
In recent years, a wide variety of organizations (notably the UN and nongovernmental organizations) have used sport as an interventionist tool to nurture peacemaking across divided communities. This paper examines and theorizes these peacemaking initiatives across the expanding 'sport, development and peace'
\end{abstract}


(SDP) sector. I begin by locating SDP projects within their historical contexts, and as significant elements within the emerging 'global civil society'. I then set out three ideal-type models of SDP project; namely, the 'technical', 'dialogical', and 'critical'. Each model is examined through a set of common social heuristics, such as its core objectives and paradigmatic methods. The models may be employed to analyse other peacemaking and development fields. The first two models are most influential among existing SDP projects; the potential benefits of the 'critical' model are also outlined.

Keywords: Sport. Development and Peace. Peacemaking. Global Civil Society.

El sector del deporte para el desarrollo y la paz: un modelo sociológico de las agencias de mantenimiento de la paz

\section{Resumen}

Recientemente, una gran variedad de organizaciones (en particular las Naciones Unidas y organizaciones no-gubernamentales) han utilizado el deporte como herramienta de intervención para la pacificación. Este artículo analiza y teoriza estas iniciativas a través de la expansión del sector de "deporte para el desarrollo y la paz" (DDP). Empiezo por la localización de los proyectos de procesamiento electrónico de datos dentro de sus contextos históricos como elementos importantes dentro de la "sociedad civil global" emergente. Entonces delimitar tres modelos de los tipos ideales de los proyectos en DDP: "técnico", "dialógico" y "crítico". Cada modelo se examina a través de un conjunto común de heurísticas sociales, tales como sus objetivos fundamentales y los métodos de paradigma. El modelo puede ser utilizado para analizar otros campos de la paz y el desarrollo. Los dos primeros modelos son algunos de los diseños más influyentes. Los beneficios potenciales del modelo "crítico" también se encuentran delimitados.

Palabras clave: Deporte. Desarrollo y Paz. Pacificación. Sociedad Civil Global.

\section{Referências}

ANHEIER, H. K.; KALDOR, M.; GLASIUS, M. (eds.). Global Civil Society Yearbook 2005/6, London: Sage, 2007.

ARMSTRONG, G. The Lords of Misrule: Football and the Rights of the Child in Liberia, West Africa, Sport in Society, 7(3): 473-502, 2004.

. The Global Footballer and the Local War-Zone: George Weah and Transnational Networks in Liberia, West Africa', Global Networks, 7(2): 230-247, 2007.

BAKER, W. J.; MANGAN, J. A. (eds.). Sport in Africa, London: Africana Publishing, 1987. 
BALE, J.; SANG, J. Kenyan Running, London: Frank Cass, 1996.

BECKLES, H. McD.; STODDART, B. (eds.). Liberation Cricket, Manchester: Manchester University Press, 1995.

BOOTH, D. The Race Game: Sport and Politics in South Africa, London: Frank Cass, 1998.

BROHM, J. M. Sport: A Prison of Measured Time, London: Pluto, 1987.

CHANDLER, D. Constructing Global Civil Society, Basingstoke: Palgrave, 2005.

DARNELL, S. Changing the World Through Sport and Play: A Post-Colonial Analysis of Canadian Volunteers Within the 'Sport for Development and Peace' Movement, unpublished $\mathrm{PhD}$ thesis, University of Toronto, 2008.

GASSER, P. K.; LEVINSEN, A. Breaking Post-War Ice: Open Fun Football Schools in Bosnia and Herzegovina, Sport in Society, 7(3): 457-472, 2004.

GOLDBLATT, D. Football Yearbook 2003-4, London: DK Publishing, 2003.

GUTTMANN, A. Games and Empires: Modern Sports and Cultural Imperialism, New York: Columbia University Press, 1994.

. The Olympics: A History of the Modern Games, Urbana: University of Illinois Press, 2002.

GUTTMANN, A.; THOMPSON, L. Japanese Sports: A History, Honolulu: University of Hawaii Press, 2001.

HOLT, R. Sport and the British, Oxford: Oxford University Press, 1989.

JAMES, C .L. R. Beyond A Boundary, London: Stanley Paul1, 963.

KALDOR, M. Global Civil Society, Cambridge: Polity, 2003. 
KEANE, J. Global Civil Society?. Cambridge: Cambridge University Press, 2003.

KEIM, M. Nation Building at Play: Sport as a Tool for Integration in Post-Apartheid South Africa, Aachen: Meyer and Meyer, 2003.

KNOWLES, M. Andragogy in Action, San Francisco: Jossey Bassey, 1984.

KORR, C.; CLOSE, M. More Than Just A Game: Football v Apartheid, London: Collins, 2008.

LANFRANCHI, P. [et.al.]. 100 Years of Football: The FIFA Centennial Book, London: Weidenfeld \& Nicolson, 2004.

MANGAN, J. A. The Games Ethic and Imperialism, London: Viking, 1985.

MASON, A. Passion of the People? Football in South America, London: Verso, 1995.

SCHULENKORF, N. Sport Events and Ethnic Reconciliation: Attempting to Create Social Change in War-Torn Sri Lanka, International Review for the Sociology of Sport, (forthcoming), 2010.

SDP IWG. Harnessing the Power of Sport for Development and Peace: Recommendations to Governments, Toronto: Right to Play, 2008.

UN General Assembly. Sport for Development and Peace: The Way Forward, Report of the Secretary-General, A/61/73, New York: United Nations, 2006.

WEBER, M. The Methodology of the Social Sciences, Glencoe, IL: Free Press, 1949.

WEBER, M. Selections in Translation, Cambridge: Cambridge University Press, 1978.

Endereço para correspondência

r.giulianotti@lboro.ac.uk

Richard Giulianotti 
DOI 10.5216/rpp.v15i3.20505

Epinal Way, Loughborough

Leicestershire LE11 3TU, Reino Unido 